\title{
Inheritance of coat colour in the field spaniel dog
}

\author{
R Robinson \\ St Stephens Nursery, Stephens Road, London W13 8HB, UK
}

(Received 22 December 1995; accepted 13 March 1996)

\begin{abstract}
Summary - The varieties of the field spaniel breed have the coat colours black, black and $\tan$, liver, liver and tan; with or without roan colouration. Retrospective analysis of litter data reveals that the colours are produced by the agouti mutant alleles solid black $\left(A^{s}\right)$ and black and $\tan \left(a^{t}\right)$, black pigmentation $B$, and liver brown $b$. Roan colouration is engendered by the gene combination $s^{p} s^{p} T T$. The breed is homozygous for long hair and the long coat enhances the effect of admixture of intermingled coloured and white hairs for the variety known as roan.
\end{abstract}

dog genetics / coat colour / field spaniel / breed

Résumé - Hérédité de la couleur du pelage chez le chien Field Spaniel. Les variétés de la race canine Field Spaniel comprennent les couleurs noir, noir et feu, foie, foie et feu; avec ou sans la couleur rouanne. Une analyse rétrospective d'observations de portées révèle que les couleurs sont dues aux allèles mutants du locus Agouti noir uniforme $\left(\mathrm{A}^{\mathrm{s}}\right)$ et noir et feu $\left(\mathrm{a}^{\mathrm{t}}\right)$, au gène de la pigmentation noire $\mathrm{B}$ et son allèle brun foie $\mathrm{b}$. Le rouan résulte de la combinaison d'un génotype récessif pour la panachure $\mathrm{s}^{\mathrm{p}} \mathrm{s}^{\mathrm{p}}$ et d'un génotype homozygote moucheté TT. La race est homozygote pour le poil long et la longueur du poil renforce les effets de mélange de poils blancs et colorés qui constituent la variété connue sous le nom de rouan.

génétique canine / couleur de robe / Field Spaniel

\section{INTRODUCTION}

Although it is possible to form generalizations for the heredity of coat colour in the dog (Little, 1957; Robinson, 1990), it has become apparent as work in the field has progressed that certain breeds possess unique mutant alleles. It is important, therefore, to investigate the inheritance of colour varieties in individual breeds. Comparatively recently, it has been shown that two alleles at the same locus, one dominant and the other recessive to wild type, can produce a completely black coat 
(Willis, 1970; Carver, 1984). It follows that it is no longer safe to assume that all black dogs are due to the same allele (Little, 1957).

Even more recently, it has been discovered that the unique harlequin pattern of the Great Dane is genetically different from the merle pattern of other breeds which it resembles phenotypically (Sponenberg, 1985; O'Sullivan and Robinson, 1989). Tweed is another colour which resembles merle but which is genetically unique to the Australian Shepherd dog (Sponenberg and Lamoreux, 1985). In the past, each of these colours would have been ascribed to the merle gene.

The present report describes an analysis of colour variation in the field spaniel, one of several breeds of the spaniel group. The breed is long coated and is bred in a number of different colour varieties. The most common variety is the self-coloured liver brown. Two less common varieties are the self-black and the black and tan. In the latter, the whole body is black with tan-coloured markings. These comprise two tan patches on the front of the chest, tan on the inside of the legs, and on the front of the legs from the carpal to the hock, together with two characteristic small tan spots above the eyes.

The roan variety is a spotted animal, with variable areas of white in the coat which are liberally interspersed with coloured hairs. Each of the previous varieties may be combined with roan, with appropriate changes for the coloured hairs.

\section{MATERIAL AND METHODS}

The investigation proceeded by an analysis of litters for the 15-year period from 1980 to 1994 inclusive, as registered with the British Kennel Club and supplemented by details of litters for the first half of 1995 and numerous litters from Sweden. Breeders were consulted in cases of doubt regarding the completeness of litters.

In total, the data consisted of 355 litters comprising 1558 pups; of these, 74 litters provided evidence of segregation of mutant alleles as summarized in table I. The frequency of phenotypes representing segregation of the alleles was accomplished by the a priori method of assessment on the assumption of near or complete ascertainment (Emery, 1976). This biometric procedure effectively allows for the non-detection of litters composed entirely of the dominant phenotype from heterozygous parents.

The completely black colour behaved as a monogenic dominant to liver, as evidenced by the first three entries of table I. The observed frequencies of segregation are in accord with expectation, as shown by the nonsignificant $\chi^{2}$ values. In confirmation of the recessive nature of liver, mating of liver to liver gave 1452 liver pups.

The black and tan colouration is relatively uncommon and this is reflected by the small amount of data on this variety. However, it is apparent that the colour segregated as recessive to both self-black and self-liver (fourth and fifth entries of table I).

The roan (spotted) varieties are relatively more common and the segregation of non-roan versus roan on the expectation of the latter being a recessive trait is shown by the final entries of table I. The precise genetics of roan are discussed later. 
All of the observed frequency segregations display close agreement with their expectations and none of the relevant $\chi^{2}$ for assessing the probability of the segregations are statistically significant.

\section{DISCUSSION}

A general exposition of the nature and heredity of coat colour in the dog may be found in Little (1957) and Robinson (1990). To comprehend the basis of the colour varieties for the field spaniel, it is necessary to briefly review the phenotypes of the relevant coat-colour mutants.

The solid black colour may be produced by either of two alleles at the agouti locus $A$. These are (1) dominant black $A^{s}$ and (2) non-agouti or recessive black $a$. Black and $\tan a^{t}$ is also a member of the agouti series of alleles and is recessive to $A^{s}$ but dominant to $a$. Black pigmentation is due to a gene $B$ which is dominant to its liver-brown allele $b$. The colour known as roan is produced by a combination of two genes, piebald white spotting $s^{p}$, which is a recessive mutant of $S$, and ticking $T$. The $T$ gene induces variable number of coloured hairs in the white areas produced by the $s^{p}$ gene. Gene $S$ is epistatic to $T$.

The predominant colour of the field spaniel is liver, as documented by the large number of inter se liver matings which produced only liver progeny. Liver is inherited as recessive to black pigmentation and is due to the well-established $b$ gene.

The solid black variety could be due to either $A^{s}$ or $a$. Of the two, the $A^{s}$ allele is indicated because if the colour is due to the $a$ allele, matings between black parents could not produce black and tan offspring as shown by table I.

Table I. Observed and expected segregation of the mutant alleles liver $(b)$, dominant black $\left(A^{s}\right)$, tan pattern $\left(a^{t}\right)$ and piebald $\left(s^{p}\right)$ in the field spaniel breed of $\operatorname{dog}$.

\begin{tabular}{lcccccc}
\hline \multirow{2}{*}{ Mating } & \multicolumn{2}{c}{ Observed } & \multicolumn{2}{c}{ Expected } & Ratio & $\chi^{2}$ \\
\hline & $B$ & $b$ & $B$ & $b$ & & \\
Black $\times$ black & 20 & 7 & 19.1 & 7.9 & $3: 1$ & 0.15 \\
Black $\times$ liver & 75 & 72 & 67.6 & 79.4 & $1: 1$ & 1.49 \\
Liver $\times$ liver & - & 1452 & - & 1452 & & \\
Black $\times$ black & $A^{s}$ & $a^{t}$ & $A^{s}$ & $a^{t}$ & & \\
Black $\times$ tan & 42 & 21 & 41.9 & 21.1 & $3: 1$ & 0.01 \\
& 7 & 6 & 6 & 7 & $1: 1$ & 2.14 \\
Black $\times$ black & $S$ & $s^{p}$ & $S$ & $s^{p}$ & & \\
Black $\times$ piebald & 50 & 24 & 50.7 & 23.3 & $3: 1$ & 0.03 \\
Piebald $\times$ piebald & 16 & 21 & 17.6 & 19.4 & $1: 1$ & 0.27 \\
\hline
\end{tabular}

See text for description of genotypes; for the last two series of matings, black includes both black and liver parents. $\chi^{2}$ values have one degree of freedom and none is significant at the $5 \%$ level. 
The genotype of roan (spotted) is $s^{p} s^{p} T T$ and the segregation data of table I relate to genes $S$ and $s^{p}$. Gene $T$ is only manifested in the white areas of $s^{p}$ and the fully coloured $S$ individuals are epistatic to it. The evidence is that $T$ is widespread, if not homozygous, in the field spaniel population. The roan colouration is enhanced by the long coat which causes a greater visual random admixture of colours than if the coat is short. The phenotype is termed roan by breeders and is not roan as strictly interpreted as a mixture of coloured/white hairs throughout the coat.

Accordingly, the genotypes of the colour varieties of the field spaniel may be

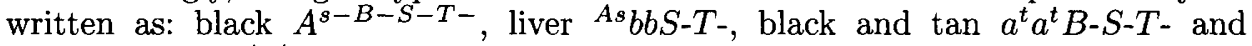
liver and $\tan a^{t} a^{t} b b S-T$-; where the dash sign indicates possible homozygosity or heterozygosity of the recessive allele. Each of the four varieties may be found combined with roan when the $s^{p}$ replaces $S$.

The investigation provided some information on the distribution of litter sizes for the breed. The range varied from one to nine pups per litter, with a mean of $4.46 \pm 0.11$ per litter. The frequency distribution was notably skewed towards the smaller litters but without statistical significance.

\section{ACKNOWLEDGMENT}

I gratefully thank P Goodwin who painstakingly collected the information which formed the basis of this study.

\section{REFERENCES}

Carver EA (1984) Coat colour genetics of the German shepherd dog. $J$ Hered 75, 247-253 Emery AEH (1976) Methodology in Medical Genetics. Churchill Livingstone, Edinburgh, $37-39$

Little CC (1957) Inheritance of Coat Colour in Dogs. Cornell University Press, New York O'Sullivan N, Robinson R (1989) Harlequin colour in the Great Dane dog. Genetica 78, $215-218$

Robinson R (1990) Genetics for Dog Breeders. Pergamon Press, Oxford

Sponenberg DP (1985) Inheritance of harlequin color in Great Danes. $J$ Hered 76, 224-225

Sponenberg DP, Lamoreux ML (1985) Inheritance of tweed: a modification of merle, in the Australian Shepherd dog. J Hered 79, 303-304

Willis MB (1976) The German Shepherd Dog. K \& R Books, Queniborough 